\title{
CÁC PHƯƠNG PHÁP QUAN TRẮC TRƯợT LỞ ĐẤT
}

\author{
L̂E THI HÀ \\ Khoa Công trình, Truờng Đại học Giao thông Vận tải, Phân hiệu tại TPHCM
}

\section{Tóm tắt:}

Bài báo giới thiệu về các phương pháp quan trắc trượ lở đất đang được ưng dụng trên thế giới. Trươt lở đất là một dạng tai biến vừa có tính chất tiềm ẩn vùa có tính chất hiểm họa, nó gây ra nhiều thiệt hại lớn và gây nguy hiểm đến tính mạng cũng nhu cuộc sống sinh hoạt của nguời dân. Vì vậy quan trắc trượt lở đất là rất cần thiết nhằm sớm phát hiện các chuyển vị và biến dạng. Trong bài báo tác giả giới thiệu một số các thiết bị đo đạc và cách thức quan trắc chuyển vị độ dốc nhằm đưa ra các giải pháp hữu hiệu có thể áp dụng đối với địa hình phức tạp ở Việt Nam.

\section{Giới thiệu chung}

Trượt lở đất đá trên sườn dốc là một dạng của tai biến địa chất, thực chất đó là quá trình dịch chuyển trọng lực các khối đất đá cấu tạo sườn dốc từ trên xuống phía dưới chân sườn dốc do tác động của các nguyên nhân (trọng lượng bản thân khối đất đá trượt, tải trọng ngoài, áp lực thủy tĩnh, áp lực thuỷ động, lực địa chấn và một số lực khác) làm mất trạng thái cân bằng ứng suất trọng lực và biến đổi tính chất cơ lý của đất đá đến mức làm mất ổn định sườn dốc. Có nhiều nguyên nhân gây trượt lở đất như cấu trúc địa chất, đặc điểm địa hình của sườn dốc, quá trình phong hoá, quá trình Karst, tác động của nước mưa đặc biệt là lượng mưa lớn và kéo dài, các hoạt động kinh tế, xây dựng của con người mà chủ yếu là cắt xén sườn dốc để làm đường, nổ mìn, san gạt để xây dựng với sự suy giảm của lớp phủ thực vật.

Ở Việt Nam, những vụ trượt lở đất gần đây tại Hòa Bình, Yên Bái, Lào Cai, Hà Giang...đã gây ra những thiệt hại nghiêm trọng. Hiện nay ở Việt Nam đã có một số công trình nghiên cứu về trượt lở đất. Một trong những dự án nổi bật nhất là "Phát triển công nghệ đánh giá rủi ro sụt trượt đất dọc theo các tuyến giao thông chính tại Việt Nam" (Thuyết minh văn kiện Dự án Hợp tác kỹ thuật sử dụng vốn ODA không hoàn lại, 2012 ).

Các nghiên cứu trên thế giới nhờ có sự hỗ trợ của nền khoa học công nghệ cao đã thu được nhiều kết quả trong vấn đề cảnh báo trượt lở đất. Tuy nhiên, những hệ thống cảnh báo thời gian thực có thể thương mại hóa là rất hiếm hoi.

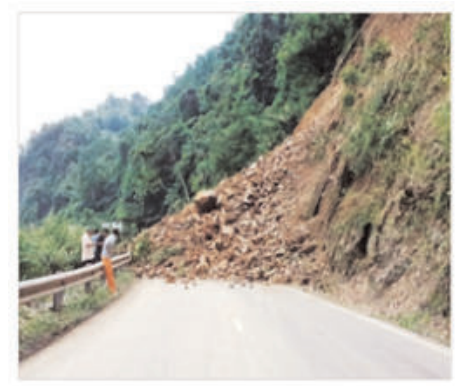

Hình 1: Hìn ảnh minh họa khu vục truợt đất

\section{Các phương pháp đo đạc quan trắc trượt lở đất}

Hệ thống giám sát sạt lở tiếp tục phát triển và cải tiến. Sự phát triển của công nghệ thông tin đang cho phép hệ thống tự động thu thập các phép đo ở mức cao tần số (vài phép đo mỗi giờ) cho phép theo dõi thời gian thực của các chuyển vị và tốc độ dịch chuyển. Hơn nữa, chi phí của một số các thiết bị giảm theo công nghệ đem lại những tiến bộ đáng kể. Một số công nghệ được kể đến như là máy toàn đạc điện tử, hệ thống GPS, hệ thống máy bay không người lái (UAVUnmanned aerial vehicle).

\subsection{Phương pháp quan trắc bằng sử dụng cảm biến GPS giá rẻ}

Việc theo dõi biến dạng là một ứng dụng rất

Ngày nhận bài: 05/11/2019, ngày chuyển phản biện: 09/11/2019, ngày chấp nhận phản biện: 15/11/2019, ngày chấp nhận đăng: 18/11/2019 
thực tiễn và đóng vai trò quan trọng vì hầu như các đối tượng đều chịu sự thay đổi theo thời gian dưới sự tác động của các yếu tố khác nhau. Các công trình xây dựng, những khu vực khai thác mỏ hay các hoạt động khai thác có nguy cơ bị sạt lở cao. Những biến đổi đó đã ảnh hưởng nghiêm trọng đến cuộc sống của con người. Để khắc phục được vấn đề đó chúng ta đã ứng dụng những tiến bộ của công nghệ đo đạc, sự phát triển vượt bậc của công nghệ thông tin, làm thay đổi nhiều công tác theo dõi biến dạng. Tuy nhiên một trong những cản trở lớn đó là giá thành của các trang thiết bị rất cao, hơn nữa phải lắp đặt tại một vị trí và phục vụ cho một mục đích duy nhất. Một trong những công nghệ được nhắc đến đó là GPS. Thiết bị thu nhận tín hiệu định vị vệ tinh GPS đang là một trong những giải pháp quan trọng trong việc quan trắc biến dạng trên thế giới. Tuy nhiên ở Việt Nam cho tới nay việc tích hợp GPS vào mục đích đó chưa được phổ biến vì việc tăng số lượng trạm GPS cũng đồng nghĩa với việc giá thành tăng. Do đó nếu chúng ta sử dụng cảm biến GPS (Geocubes) có giá thành rẻ để xây dựng giải pháp quan trắc trượt lở đất có khả năng đáp ứng được những yêu cầu kỹ thuật mà giá thành cũng không quá cao.

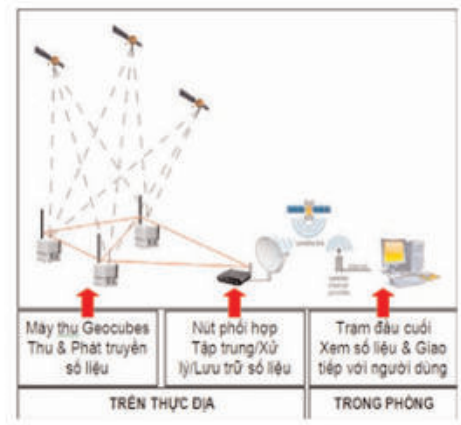

Hình 2.1: Mô hình lưới quan trắc biến dạng sủ dụng GPS giá rẻ Geocubes

Hệ thống Geocubes là một mạng lưới các máy thu quan trắc GPS. Mỗi máy thu có một ăng-ten tần số vô tuyến cho phép giao tiếp với các máy khác và kèm theo bộ ghi dữ liệu. Hệ thống hoạt động bằng cách đo khoảng cách tương đối giữa một điểm tham chiếu và các máy thu khác trong mạng. Dữ liệu thu thập được là tọa độ $\mathrm{x}, \mathrm{y}, \mathrm{z}$ của điểm trong không gian 3 chiều. Hệ thống mạng này cho độ chính xác cỡ milimet và độ phân giải thời gian cao. Số lượng máy thu có thể lên đến 100 máy kết hợp với một bộ ghi dữ liệu trong vòng bán kính tối đa $15 \mathrm{~km}$ cho toàn bộ mạng. Ngoài ra, khoảng cách tối đa giữa các máy thu, trong điều kiện thời tiết lý tưởng và không có vật cản lên đến $200 \mathrm{~m}$ với việc sử dụng một ăng ten trong (cấu hình mặc định) và 1000 $m$ với ăng ten ngoài [7],[8]. Kích thước máy thu nhỏ cho phép các máy thu riêng lẻ được di dời cho phù hợp nhất với xu hướng dịch chuyển lở đất. Một ví dụ điển hình đó là ứng dụng của hệ thống quan trắc các mối nguy trên mặt đất, đặc biệt là trượt lở đất ảnh hưởng đến hành lang giao thông ở Canada.

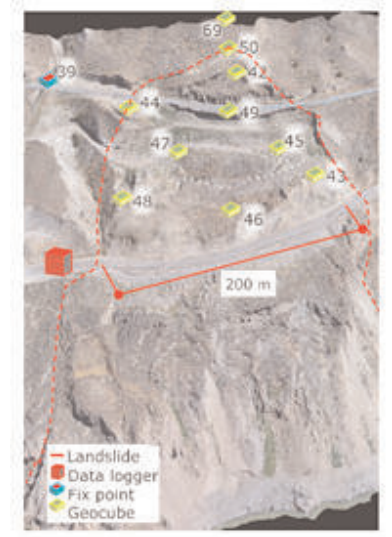

Hình 2.2: Phân phối mạng Geocubes ở khu vục có nguy cơ trươt lở đất

Hệ thống gồm 11 máy thu Geocubes, 9 máy có ăngten bên trong và 2 máy có ăngten bên ngoài. Bảy trong số mười một geocubes được đặt ở những vị trí có nguy cơ trượt lở (Số $42,43,45,46,47,48,49$, Hình 2.2). Hai máy nằm bên ngoài sạt lở gần đường viền của vết nứt 1 (Số 44, 50). Cách đường cao tốc $30 \mathrm{~m}$ ở phía trên vết nứt đặt máy số 69. Điểm tham chiếu xem xét tại một địa điểm cố định (số 39). Sự phân bố của các máy thu trên khu vực lở đất đạt khoảng cách tối đa $90 \mathrm{~m}$ giữa máy thu tại số 39 và số 44 . Khoảng cách tối đa đến bộ ghi dữ liệu với máy số 69 là $310 \mathrm{~m}$. Các máy thu được đặt trong hộp chữ $U$ mạ kẽm đặt xuống đất và ló ra $30 \mathrm{~cm}$ đến $100 \mathrm{~cm}$ trên mặt đất. Điểm cố định được bắt 
vít vào khóa bê tông khối 2,0 mét trên mặt đất. Thao tác này sẽ giúp dễ dàng sửa đổi và giải quyết các vấn đề tín hiệu trong mạng lưới geocubes hoặc với các vệ tinh. Mỗi một máy thu geocube được cung cấp bởi các tấm pin mặt trời trong vòng khoảng 200 ngày điện mà không cần yêu cầu nạp lại từ bảng điều khiển năng lượng mặt trời. Dữ liệu từ mỗi máy được thu thập sau 60 giây và được lưu trữ trong bộ ghi dữ liệu. Mặc dù mạng geocube được thiết kế để truy cập qua internet, kết nối để xử lý gần thời gian thực nhưng gặp khó khăn khi cung cấp từ xa cho bộ ghi dữ liệu. Do đó, ở giai đoạn này, dữ liệu được truyền thu thập và xử lý sau định kỳ.

Công tác giám sát đường trượt với bán kính $16 \mathrm{~km}$ bằng hệ thống geocubes đã chứng thực và nâng cao hiệu quả về quan trắc trượt lở đất ở Canada [4].

\subsection{Phương pháp quan trắc bằng sử dụng máy toàn đạc điện tử (Total Station)}

Thiết kế một hệ thống quan trắc trượt lở đất là một quy trình kỹ lưỡng phải có đầy đủ thông tin và cung cấp một số liệu cần thiết nhằm giảm thiểu rủi ro. Thiết bị cần thiết cho công tác quan trắc gồm một trạm máy toàn đạc, trạm trú ẩn, thiết bị đo điều kiện khí quyển, đèn hiệu trụ cột (để chuyển và đèn hiệu tham chiếu) và gương đặt tại các điểm quan trắc [12].

\subsubsection{Thiết lập trạm điều khiển}

Trạm điều khiển đặt tại điểm tọa độ $(\mathrm{X}, \mathrm{Y})$ và độ cao $(Z)$ được xác định và từ đó có thể thực hiện các phép đo đến một số điểm tham chiếu. Khảo sát bằng máy toàn đạc và gương đòi hỏi ba loại điểm là: điểm chuyển, điểm tham chiếu và điểm giám sát. Các điểm chuyển và tham chiếu là một phần của mạng lưới.

Cả hai đèn hiệu chuyển và tham chiếu phải được định vị để đảm bảo tầm nhìn không bị cản trở giữa các đèn hiệu nhưng không nằm ở vị trí không ổn định và nguy hiểm, tức là quá gần với đỉnh tường [12]. Để quan trắc chính xác, mạng điều khiển phải có một nhóm tối thiểu gồm bốn đèn hiệu trụ định tâm bắt buộc (có thể tạo thành một hình tứ giác)

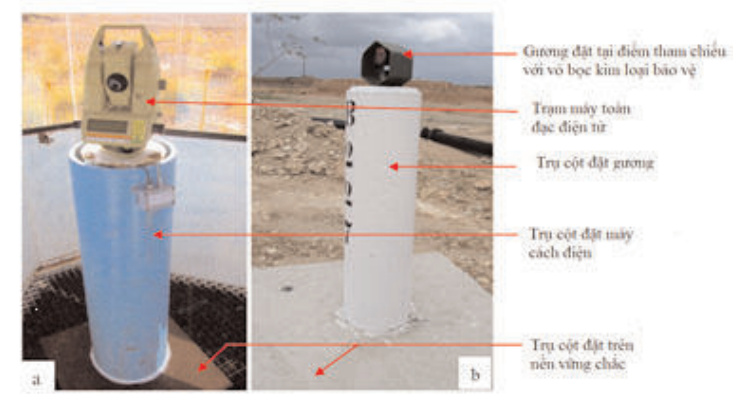

Hình 2.3: Đèn hiệu chuyển nhượng và đèn hiệu tham chiếu tuoong úng (Nguồn [12] Thomas, 2011)

\subsubsection{Xây dưng nơi trú ẩn tại đèn hiệu} chuyển nhượng

Để bảo quản các thiết bị máy móc khỏi đá bay, các hoạt động nổ mìn, khói bụi, và thời tiết một nơi trú ẩn bảo vệ phải được xây dựng trên đèn hiệu chuyển giao mà RTS (Robotic Total Station) sẽ được thiết lập như trong hình 2.4. Nếu hầm bảo vệ đèn hiệu được làm từ tấm kim loại, phần bên trong phải được cách nhiệt để giảm sinh nhiệt từ ánh sáng mặt trời. Phần bên ngoài cũng nên được sơn màu trắng để giảm ảnh hưởng của nhiệt từ ánh sáng mặt trời. Nguồn năng lượng, tức là pin để cung cấp cho RTS chỉ có thể hoạt động trong một khoảng thời gian giới hạn trước khi phải sạc lại. Để khắc phục vấn đề này, RTS có thể được cung cấp năng lượng bằng cách sử dụng nguồn năng lượng bên ngoài như năng lượng mặt trời (như trong hình 2.4a) hoặc máy phát dự phòng.

Việc giám sát thường được thực hiện thông qua kính như trong hình 2.4 b. Các thuộc tính của kính như hình dạng, độ dày và màu sắc (mức độ màu) phải được lưu ý trong quá trình lựa chọn. Khoảng cách giữa kính cửa sổ và trạm máy toàn đạc cũng phải được giữ ở mức tối thiểu. Hình $2.4 \mathrm{a}$ và $2.4 \mathrm{~b}$ cho thấy một trạm máy trú ẩn điển hình được xây dựng trên đèn hiệu chuyển tại một khu vực khai thác. 


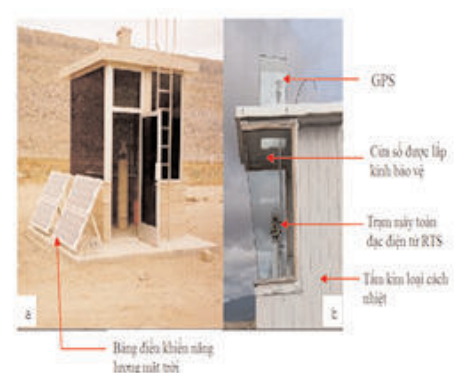

Hình 2.4: a - Nơi trú ẩn RTS với các tấm năng luợng mặt trời, b - Noi trú ẩn RTS /GPS điển hình (nguồn: [3].Anna Szostak-Chrzanowski, Adam Chrzanowski, 2008).

\subsubsection{Lắp đặt gương tại điểm quan trắc}

Việc lắp đặt gương được thực hiện ở giai đoạn đầu của hoạt động khai thác tại khu vực có khả năng xảy ra sự cố trượt lở đất. Tất cả các gương được đặt vào lỗ khoan và cố định chắc chắn bằng việc phun vữa trong mỗi thanh gương. Để có tính đồng nhất, người ta sử dụng gương phản xạ giống hệt nhau.

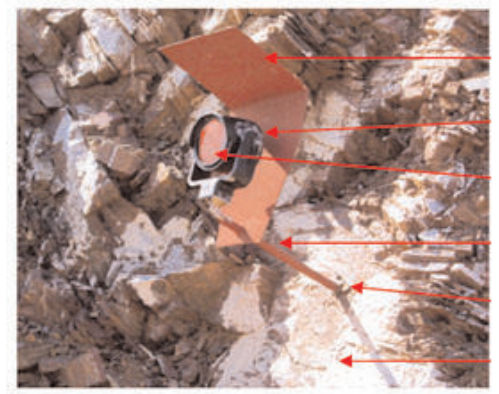

Hình 2.5: Guong được lắp đặt tại điểm quan trắc (Nguồn [12] Thomas, 2011)

Do quá trình hoạt động khai thác, RTS có thể không đo được đến gương vì bụi phủ nhiều trên bề mặt gương. Vì vậy việc thiết kế và đặt gương phải hết sức chú ý để đạt kết quả tốt trong quá trình đo đạc.

\subsubsection{Thu thập và xủ lý số liệu}

Việc sử dụng RTS cho công tác quan trắc là một cách phổ biến vì nó có thể cung cấp việc thu thập dữ liệu từ xa liên tục trong 24 giờ để phân tích và cảnh báo để cảnh báo nhân viên về các vấn đề ổn định mặt đất [2]. Các quan sát tổng đài bằng phương pháp thủ công rất tốn thời gian, tốn nhiều công sức và có khả năng xảy ra lỗi của con người khi ghi dữ liệu đo đạc. Mặc dù các hệ thống thông thường phù hợp để theo dõi đột xuất, giám sát liên tục đòi hỏi các hệ thống tiên tiến hơn để đối phó với lượng dữ liệu được ghi lại [5]. Việc sử dụng các trạm tổng đã trở nên phổ biến do tính linh hoạt, tốc độ cao, hiệu quả và độ chính xác cao. Khi đề cập đến tính linh hoạt trong trường hợp này, nó có nghĩa là khả năng của công cụ tìm thấy gương, đọc và lưu trữ dữ liệu. Khoảng thời gian đo có thể được đặt theo yêu cầu của chương trình đo và khoảng thời gian đo có nguy cơ cao có thể được đặt theo mức độ ưu tiên, cung cấp cho việc giám sát các khu vực đó thường xuyên hơn. Các khảo sát giám sát sử dụng hai nguồn dữ liệu, cụ thể là dữ liệu được đo bằng RTS (Robotic Total Station) (ví dụ: khoảng cách và góc) và dữ liệu nằm ngoài tổng đài (ví dụ: cảm biến khí tượng). Dữ liệu bên ngoài trạm tổng là dữ liệu bổ sung (nghĩa là các phép đo điều kiện khí quyển, tức là nhiệt độ môi trường và áp suất khí quyển, để điều chỉnh khí quyển). Những thay đổi trong điều kiện thời tiết, như mưa lớn và sương mù, cản trở rất lớn việc theo dõi gương. Để khắc phục điều này, thiết bị có thể được che chở dẫn đến các phép đo được thực hiện qua bề mặt kính. Kinh nghiệm của các tác giả trong quá trình đo để kiểm tra tác động của kính đối với các phép đo khoảng cách của trạm cho thấy cả lượng mưa và sương mù đều có tác động đáng kể đến kết quả thể hiện trong Hình 2.6 đến 2.7 .

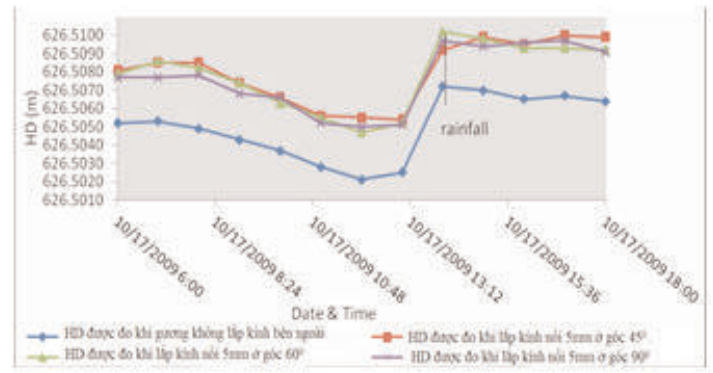

Hình 2.6: Đồ thị đo HD đến gưong, chỉ hiệu chỉnh cho hằng số gưong và hệ số tỷ lệ. (Nguồn [13] T.B. Afenil, F.T. Cawood1, 2013) 


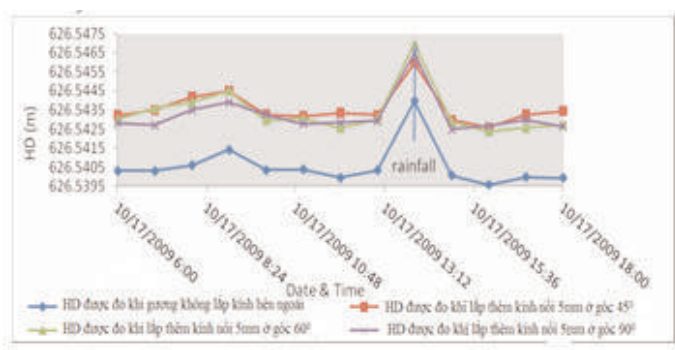

Hìn 2.7: Đồ thị đo HD đến gưong, sau khi có tất cả số hiệu chỉnh. (Nguồn [13] T.B. Afenil,

F.T. Cawood1, 2013)

Đo đạc trong điều kiện thời tiết sương mù như hình 2.6 và 2.7 cho thấy rằng toàn bộ trạm không thể thu được bất kỳ dữ liệu nào trong tầm nhìn kém, thiết bị chỉ có thể đo tốt khi thời tiết được cải thiện. Do lượng mưa và điều kiện thời tiết sương mù có ảnh hưởng tạm thời vì vậy có thể đề xuất kết hợp nhiều hơn một số kỹ thuật giám sát (nhiều công cụ giám sát) để bổ sung trạm trong hai điều kiện bất lợi này. Tuy nhiên cần lưu ý tín hiệu radar không truyền đi được với lượng mưa lớn và ảnh hưởng của khí quyển có thể làm hỏng kết quả của toàn bộ hoạt động giám sát nếu không được phục vụ tốt.

\subsection{Phương pháp quan trắc bằng sử dụng hệ thống $U A V$}

Trong những năm gần đây việc sử dụng các thiết bị UAV ngày càng trở nên phổ biến trong các lĩnh vực đặc biệt là để phục vụ công tác phân tích trượt lở đất đang còn khá mới mẻ ở Việt Nam. Kỹ thuật này có thể đóng một vai trò quan trọng trong quản lý rủi ro trượt lở đất, vì chúng cho phép thể hiện các bề mặt lớn với lấy mẫu không gian dày đặc, mang lại lợi thế rõ ràng hơn đối với các phương pháp đo truyền thống (như GPS và toàn đạc điện tử). Trái lại việc cung cấp dữ liệu lại chính xác và giới hạn ở một số lượng nhỏ các điểm quan trắc. Công nghệ sử dụng UAV có khả năng tiếp cận những khu vực phức tạp hoặc những điểm trước đây không thể tiếp cận, đồng thời nó cung cấp cho người dùng các ảnh chụp, video, lưu trữ dữ liệu...Đặc biệt tại những khu vực được coi là nguy hiểm đối với cán bộ thực địa như vách núi, bờ lở...
Một hệ thống thiết bị bay không người lái cơ bản bao gồm một khung máy bay, hệ thống đẩy, máy lái tự động gắn liền thân và trạm điều khiển mặt đất. Hai dòng thiết bị phổ biến nhất là thiết bị bay đa mô-tơ (thường gồm 4,6 hoặc 8 cánh quạt cố định) và thiết bị bay cánh cố định. Thiết bị bay đa mô-tơ có khả năng di chuyển tốt hơn so với thiết bị bay cánh cố định nhưng thường có thời gian bay ngắn hơn.

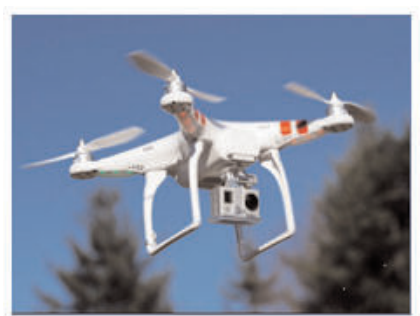

Hình 2.8: Thiết bi UAV

Thiết bị bay không người lái được điều khiển từ xa bằng cách sử dụng một thiết bị điều khiển vô tuyến (trạm điều khiển mặt đất) hoặc bay tự động bằng cách sử dụng máy lái tự động liền thân máy. Máy lái tự động có thể đi theo con đường bay được lập trình sẵn thông qua xử lý dữ liệu về vị trí và định vị từ hệ thống định vị vệ tinh toàn cầu (GNSS) và thiết bị thu và đo quán tính toàn cầu (IMU). Trạm điều khiển mặt đất nhận dữ liệu về chuyến bay như vị trí thiết bị bay, độ cao, tốc độ và trạng thái pin thông qua kết nối vô tuyến từ xa. Người vận hành thiết bị giám sát dữ liệu chuyến bay trong quá trình thiết bị đang bay và có thể có can thiệp thủ công bất cứ lúc nào. Các biện pháp an toàn được tích hợp vào hầu hết các thiết bị bay đa mô-tơ để giảm khả năng xảy ra sự cố do pin yếu hoặc mất liên lạc với trạm điều khiển mặt đất [11].

Ví dụ về một cuộc kiểm tra định kỳ đã được thực hiện tại làng Ricasoli (Thung lũng sông Upper Arno, Tuscany, Italy;), để đánh giá tiềm năng của UAV trong công tác quan trắc trượt lở đất. Cụ thể, một cuộc khảo sát thu được ảnh đa chiều khi thực hiện cho sườn phía bắc của Ricasoli. Hình ảnh được xác định ở độ phân giải rất cao, qua đó có thể so sánh các đặc điểm hình thái của độ dốc và sự tiến hóa của chúng theo thời gian. Cuộc khảo sát được thực hiện bằng 
máy bay không người lái đa năng (Saturn) với khung gầm hình tròn sáng tạo, được thiết kế, chế tạo và cấp bằng sáng chế bởi Khoa Khoa học Trái đất của Đại học Florence (Hình 2.9). Các hình ảnh được xử lý bằng phần mềm Agisoft Photoscan Professional [1] và dữ liệu kết quả được phân tích liên quan đến sử dụng hệ thống thông tin địa lý (GIS) bằng gói ESRI ArcGIS. Ba đám mây điểm định dạng 3D thu được sau một vài tháng được sử dụng để xây dựng DTM có độ phân giải cao $(0,05 \mathrm{~m} /$ pix) (Hình 2.9). Các DTM được so sánh để phát hiện bất kỳ thay đổi hình thái nào giữa ba lần bay, để mô tả đặc điểm của lở đất và chỉ ra chính xác các đặc điểm như các chỉ số của các khu vực dễ bị sạt lở trên sườn dốc (Hình 2.9). Kết quả là, hai vụ lở đất đã được phát hiện thông qua đặc trưng, bề mặt mở rộng diện tích, khối lượng và sự biến đổi theo thời gian. Phạm vi và hình ảnh tổng thể của các khu vực ở Ricasoli được tóm tắt trong Bảng 1 . Độ dốc hiện đang được theo dõi bằng cách thực hiện các khảo sát trên không lặp lại, và sự tiến hóa lở đất được đánh giá đang được sử dụng làm đầu vào cho kế hoạch giảm thiểu hiện tại.

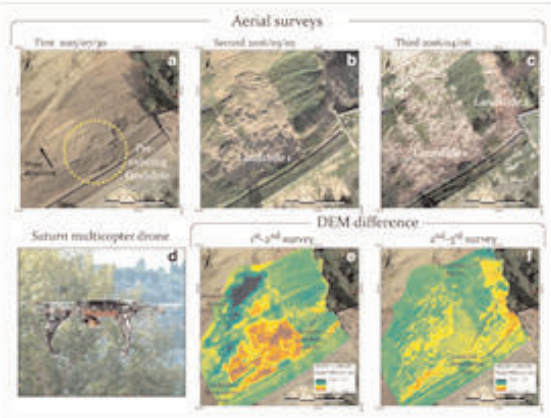

Hinh 2.9: (a), (b), (c) Anh thu đurợc trong ba cuộc khảo sát tại làng Ricasoli bằng một máy ảnh đặc biệt gắn trên UAV Saturn, (d) và (e và f) sự khác biệt về chiều cao được tính bằng DTM độ phân giải cao. Các đặc điểm chính của vùng lở đất được phát hiện và phân tích dựa trên kết quả so sánh DTM (nguồn [10]. Nicola Casagli, William Frodella, Ping Jung Lu, 2017)

\section{Kết luận}

Ở Việt Nam trong những năm gần đây do tác động của biến đổi khí hậu, thiên tai ngày càng bất thường, gây nhiều thiệt hại về người và tài sản. Một trong những thiên tai đặc biệt nghiêm trọng đó là trượt lở đất, đá. Trượt lở đất ở các sườn dốc hết sức nguy hiểm và phức tạp. Do đó công tác quan trắc trượt lở là hết sức cần thiết, nhằm sớm phát hiện các chuyển vị và biến dạng có thể dẫn đến mối nguy hiểm cho vật chịu tác động.

- Phương pháp quan trắc bằng sử dụng GPS giá rẻ cho thấy rất linh hoạt, cho phép di dời các máy thu và thể hiện khả năng thích ứng với các điều kiện địa hình đa dạng. Nhưng ứng dụng hệ thống liên quan đến các yêu cầu về năng lượng và kết nối internet. Tuy nhiên đối với địa hình và khí hậu ở Việt Nam đặc biệt là vào mùa đông những địa điểm xa hoặc nơi ánh sáng mặt trời có thể bị hạn chế trong thời gian cung cấp điện.

- Phương pháp quan trắc bằng sử dụng máy toàn đạc điện tử (Total Station) cũng khá linh hoạt, cho độ chính xác cao và hiệu quả đối với điều kiện địa hình phức tạp ở nước ta. Tuy nhiên với những khu vực có lượng mưa nhiều và sương mù dày đặc sẽ làm cản trở đến công tác đo đạc.

- Phương pháp quan trắc bằng sử dụng hệ thống máy UAV với ưu điểm là một hệ thống gọn nhẹ, thuận tiện di chuyển và đo đạc ngoài thực địa. Phù hợp với điều kiện địa hình ở Việt Nam như đồng bằng và trung du, vùng ven sông, ven biển, địa hình khó khăn, nguy hiểm...Tuy nhiên đây là công nghệ khá mới mẻ ở Việt Nam do đó người sử dụng cần được đào tạo bài bản và kỹ năng điều khiển bay chụp. Phương pháp còn

Bảng 1: Mức độ và khối lượng của các vu lở đất xảy ra ở suoòn phía bắc của Ricasoli

\begin{tabular}{|c|c|c|c|}
\hline Mức sạt lở & Thời gian xảy ra sạt lở & Độ rộng $(\mathrm{m} 2)$ & $\begin{array}{c}\text { Thề tích ước lượng } \\
\text { (m3 ) }\end{array}$ \\
\hline Mức sạt lở 1 & $01 / 03 / 2016$ & 950 & 480 \\
\hline Mức sạt lở 2 & $09 / 03 / 2016$ & 320 & 70 \\
\hline
\end{tabular}


phụ thuộc vào điều kiện thời tiết và phải tránh những khu vực cấm bay.

Với mỗi phương pháp đều có ưu nhược điểm, vì vậy để nâng cao độ chính xác trong công tác quan trắc trượt lở đất ứng dụng ở Việt Nam cần áp dụng kêt hợp các phương pháp để cho hiệu quả hơn. $\bigcirc$

\section{Tài liệu tham khảo}

[1]. Agisoft LLC. 2016. Agisoft PhotoScan Professional v. 1.2.4. available at http://www.agisoft.com.

[2]. Afeni, T.B., 2011, An Approach to Eradicate the Effects of Atmospheric Variations on Total Station Distance Measurement in a Surface Mine Environment. The impact of taking measurement through a glass medium. $\mathrm{PhD}$ Thesis, University of the Witwatersrand, Johannesburg.

[3]. Anna Szostak-Chrzanowski, Adam Chrzanowski, 2008 ' Interdisciplinary approach to monitoring, analysis, and modeling of deformations', Canadian Centre for Geodetic Engineering, University of New Brunswick, Canada.

[4]. Cost-effective Landslide Monitoring GPS System: Characteristics, Implementation and Results

[5]. Jooste, M.A. and Cawood, F.T., 2006, 'Survey slope stability monitoring: Lessons from Venetia Diamond Mine'. Proceedings of the International Symposium on Stability of Rock Slopes in Open Pit Mining and Civil Engineering, The South African Institute of Mining and Metallurgy, Symposium Series 44, pp $361-374$.

[6]. Kylia, 2016a. Geo3 Principles. https://ophelia-sensors.com/en_GB/knowledgecenter, Paris, France.

[7]. Kylia, 2016b. Geo3 RF white paper, https://ophelia-sensors.com/en_GB/knowledgecenter, Paris, France.

[8]. Kylia, 2016c. Geocube, https://opheliasensors.com/en_GB/knowledge-center, Paris, France.

[9] Agricultural University (EJPAU), vol. 11 no. 2, viewed 30 January 2011 $<$ http://www.ejpau.media.pl/volume11/issue2/ar t-29.html $>$.

[10]. Nicola Casagli, William Frodella ,Ping Jung Lu ,2017. Spaceborne, UAV and groundbased remote sensing techniques for landslide mapping, monitoring and early warning, Department of Earth Sciences, University of Florence, Via G. La Pira 4, 50121 Florence, Italy

[11]. Roman Sorgenfrei, Khảo sát vùng ven biển - sử dụng thiết bị bay không người lái (UAVs)

[12]. Thomas, H.G., 2011, Slope stability prism monitoring: A guide for practising mine surveyors. Unpublished M.Sc dissertation, University of the Witwatersrand, Johannesburg, South Africa.

[13]. T.B. Afeni1, F.T. Cawood1, 2013, Slope Monitoring using Total Station: What are the Challenges and How Should These be Mitigated? South African Journal of Geomatics. $\bigcirc$

\section{Summary}

\section{Methods of consideration of sliding land}

\section{Le Thi Ha, University of Transport and Communications, Campus in Ho Chi Minh City}

The article introduces the landslide monitoring methods being applied in the world. Slope instability can be expected at any surface mining operation, but unforeseen movements are dangerous to life and destroy property. There fore landslide monitoring is necessary to detect displacements and deformation soon. In the article, the author introduces a number of measuring devices and ways of monitoring the displacement of slopes to provide effective solutions that can be applied to complex terrain in Vietnam. $\mathrm{O}$ 